Article

\title{
Ground-Penetrating Radar to explore spatial variations of thaw thickness and internal structure in the active layer of Tibetan Plateau based on Reverse time Migration Method
}

\author{
Xinglin $\mathrm{Lu}^{1}$, Ao Song ${ }^{1}$, Jiwen Xiao ${ }^{1}$, Zhenning $\mathrm{Ma}^{1}$, Rongyi Qian ${ }^{1, *}$ and Qingbai $\mathrm{Qu}^{2}$ \\ 1 School of Geophysics and Information Technology, China University of Geosciences, Beijing, 100083, \\ China; 1x1@cugb.edu.cn (X.L); songao_cugb@163.com (A.S); xjw@cugb.edu.cn (J.W) ; \\ 2110170030@cugb.edu.cn (Z.N); rongyiqian@cugb.edu.cn (R.Y) \\ 2 State Key Laboratory of Frozen Soil Engineering, Cold and Arid Region Environmental and Engineering Research \\ Institute, Chinese Academy of Sciences, Lanzhou, 730000, China; qbwu@1zbac.cn (Q.B) \\ * Correspondence: rongyiqian@cugb.edu.cn; Tel.: +86-010-82322417
}

\begin{abstract}
The active layer thickness (ALT) is affected by local soil material and surface vegetation coverage in Tibetan plateau permafrost region. The human activities and engineering construction along the Qinghai-Tibet Highway (QTH) destroyed the surface vegetation coverage, which have seriously influenced the ALT and heat exchange balance. Meanwhile, the changes of the detailed internal structure in the active layer will affect the stability of engineering infrastructure. Groundpenetrating radar (GPR) was used to detect the ALT in the permafrost region. However, researches on the detailed structure of the active layer and spatial variation information of ALT are rare, the main reason given for this is that the lack of advanced imaging techniques to enhance the GPR images. In this paper, the researchers focus on solving this problem by applying the reverse time migration (RTM) method to GPR field data acquired in the Beiluhe region. Analyses of the results led to conclusions as follows: a) The RTM algorithm is proved to be accurate for imaging the characteristics of the active layer through the dielectric constant model obtained by common midpoint and GPR data velocity analysis. b) The result of RTM profiles show the loose structure and graben-like fine internal structure. Combining with drill data and soil materials information, the researchers deduce the graben-like structure might be coarse gravel layer, which may be related to subgrade settlements in some local area. c) The 2D contour maps not only show the spatial variation feature of ALT at two sides of the highway, but also can compensate the defect of the research for single 2D survey line. The ALT is about $0.6 \sim 0.8 \mathrm{~m}$ in most areas, and about $0.8 \sim 0.9 \mathrm{~m}$ near the highway at west side of the QTH on the 2D contour maps. From the RTM interpretation profile, the closer to the plash, the deeper thawed active layer. The detailed internal structure of the active layer and 2D contour maps of ALT have great significance for the study of fine internal structure and the characteristic of ALT spatial variation in the Tibetan plateau under the background of climatic change.
\end{abstract}

Keywords: Qinghai Tibet Plateau; permafrost; active layer thickness; ground-penetrating radar; reverse time migration

\section{Introduction}

The permafrost is very sensitive to the change of ecological environment and human activities due to global warming [1-3]. The acceleration of permafrost degradation, deepening of permafrost active depth and disappearance of island permafrost are reported on the Tibetan [4-6]. The change of the active layer thickness (ALT) has greatly impact on the balance of ecosystems and stability of 
engineering infrastructures in the permafrost region [7]. The construction of engineering infrastructures, such as the Qinghai-Tibet Highway (QTH) and the tower foundation of power transmitter line [8-9], have dramatically altered the original structure of groundwater and surface water resources. Meanwhile, the degradation of permafrost will also affect the stability of engineering construction in permafrost regions. For example, the QTH have appeared some deformations and cracks on the roadbed [10]. It can be noted that some researchers have discussed the ground ice and permafrost table [11], the characteristic of ice-rich permafrost [12] and thermokarst lakes [13-16] near the QTH. Wu et al [17-18] concluded that the ALT was closely related to soil temperature at $50 \mathrm{~cm}$ depth in the Qinghai-Tibet Plateau (QTP). Pang et al [7] simulated the potential changes of ALT based on Kudryavtsev's formulas and discussed the spatial variability in the ALT on the QTP. Li et al [4] estimated the ALT model based on monitored data from 10 observation fields along the QTH in permafrost region. Yu et al [19] pointed out that the embankment settlement and deformations in permafrost region results from thaw settlement. Peng et al [5] used the monitoring data from 13 typical monitoring sites along the QTH to analyze the climate changing and stability of engineering construction. $\mathrm{Wu}$ et al [18] discussed the variations in ALT and permafrost temperature in the numbers of alpine ecosystems from 2002 to 2012 in Beiluhe region. Yin et al [20] concluded the spatial variations of ALT in different cover types using satellite imagery. The change of ALT is mainly related to surface cover types and ground temperature. The local fine structure in active layer can reflect the characteristics of soil creep which can better understand the mechanism of embankment settlement and the process of crack formation. However, it is rarely found studies of the local fine structure in active layer and direct investigations of ALT spatial variations using reliable technique.

Ground penetrating radar (GPR) is the most powerful and widely used geophysical tool in permafrost studies [21-28]. It is an efficient and meticulous approach to study the permafrost distribution characteristics, ALT, and the evolution process by using GPR in conjunction with some invasive geological explorations, such as trenching, coring, and boring as the calibration. From preliminary studies $[7,25,29]$, due to the complexity in geomorphology and meteorology in the Tibetan plateau, there are some indications showing that the water content, and the ALT may have significant short-wavelength lateral variation. Nevertheless, no existing studies can identify the detailed internal structure of the active layer of the permafrost in this area. The process of migration can improve the resolution of GPR data which have more diffraction and low single to noise ratio (S/N). Compared with the classic migration methods [30], the reverse time migration (RTM) method can provide higher resolution imaging to facilitate better interpretation. At present, the GPR RTM method is decoupled from Maxwell's equation for the flat topography using Cartesian coordinate [31].

This paper applies the conventional finite-difference time domain (FDTD)-RTM algorithm from the Maxwell's equation to the zero-offset GPR data acquired at the site of Beiluhe in the Tibetan plateau. Combining the RTM sections from real data, the characteristic of vegetation coverage and soil material, the researchers will mainly embrace the following contents:

(a) The researchers will analyze the raw GPR data and effects of RTM imaging;

(b) Combining with soil material and type of frozen soil, the researchers will analyze the characteristic of the fine internal structure in the active layer, and discuss the formation mechanism of the graben-like structure. 
(c) Combining with surface vegetation coverage and characteristic of landform, the researchers apply the 2-D contour maps of the ALT to analyze the spatial variation features of the ALT at two sides of the QTH, and discuss the relationship among ALT, vegetation coverage and plash.

Researching the fine internal structure and thawed ALT based on GPR RTM profiles, the researchers expect to provide more information of freeze-thaw cycle in active layer and help to understand the characteristic of soil creep and mechanism of embankment settlement along the QTH.

\section{Materials and Methods}

\subsection{Study area}

Beiluhe region $\left(92.9318^{\circ} \mathrm{E}, 34.8214^{\circ} \mathrm{N}\right.$, and see Figure 1$)$ is located in central Tibetan plateau. In this area, the terrain is quite gentle, the elevation change is from $4600 \mathrm{~m}$ to $4700 \mathrm{~m}$. The formations mainly compose of Quaternary silt, pluvial fine sand, silt and silty clay layer, overlying peat layer in the local region. The entire area developed from weathered Tertiary muds and sands. Permafrost types mainly compose of ice-rich soil and frozen soil, ice in soil in local region. The thickness of the permafrost is $50 \sim 80 \mathrm{~m}$, ALT ranged from $1.6 \mathrm{~m}$ to $3.4 \mathrm{~m}$, and the upper interface of the permafrost is -1.8 -2.2 m over the last 30 years [16]. The average temperatures rise by about 0.3 to $0.4{ }^{\circ} \mathrm{C}$ in the Tibetan plateau due to global warming. It causes degradation of permafrost region, increase of the ALT, disappearance of local island permafrost. The influence of human engineering activities, such as the Tibetan highway, making the lithology of subsurface and coverage of vegetation even more non-uniform. The ALT in the local scale has changed in this region.
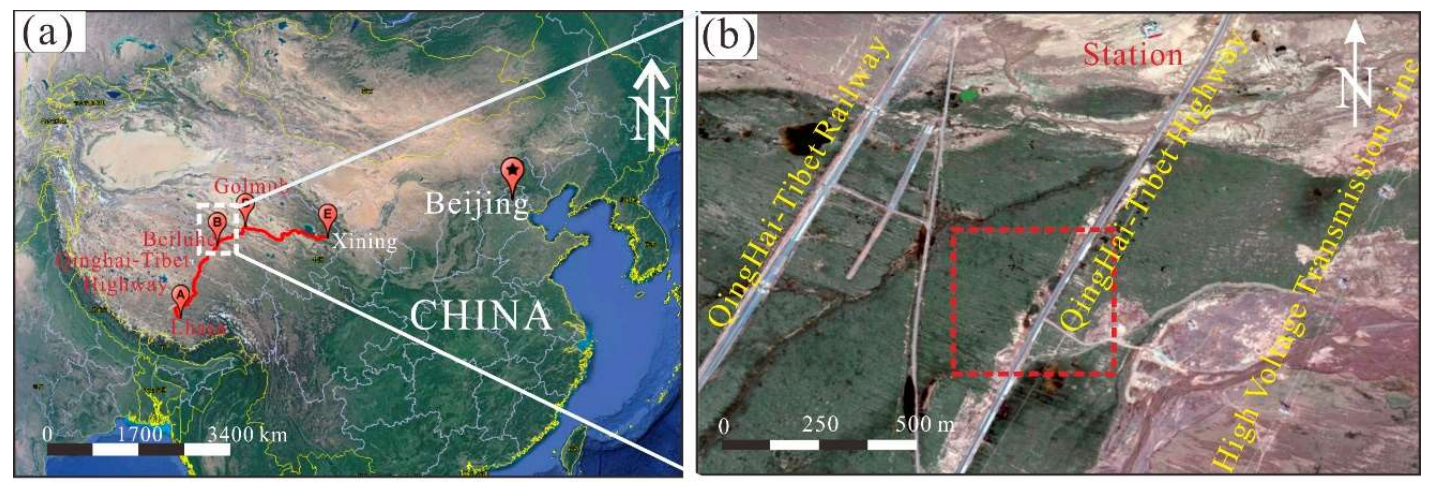

Figure 1. The location in Beiluhe permafrost region, the red box is study area (b).

\subsection{GPR data}

In June 2015, the GSSI SIR30E GPR apparatus (Geophysical Survey Systems, Inc., Nashua, New Hampshire, USA) were used for the characterization of the permafrost on both sides of the QTH. The researchers designed 60 survey lines with a length of about $200 \mathrm{~m}$ (Figure 2).The antenna frequency is $400 \mathrm{MHz}$, the sampling interval is $0.097 \mathrm{~ns}$, with a total number of 1024 samples in one trace, the line spacing is $2 \mathrm{~m}$. The researchers also conducted a $100 \mathrm{MHz}$ antenna in step $10 \mathrm{~cm}$ to move in the opposite direction antenna, and obtained the common midpoint (CMP) gather for estimating the formation velocity (the red spot in Figure 2). The researchers took a test pit at the west side of the Tibetan highway (Figure 3b), and found the thawed ALT is about $53 \mathrm{~cm}$ during the period of the GPR surveys. 


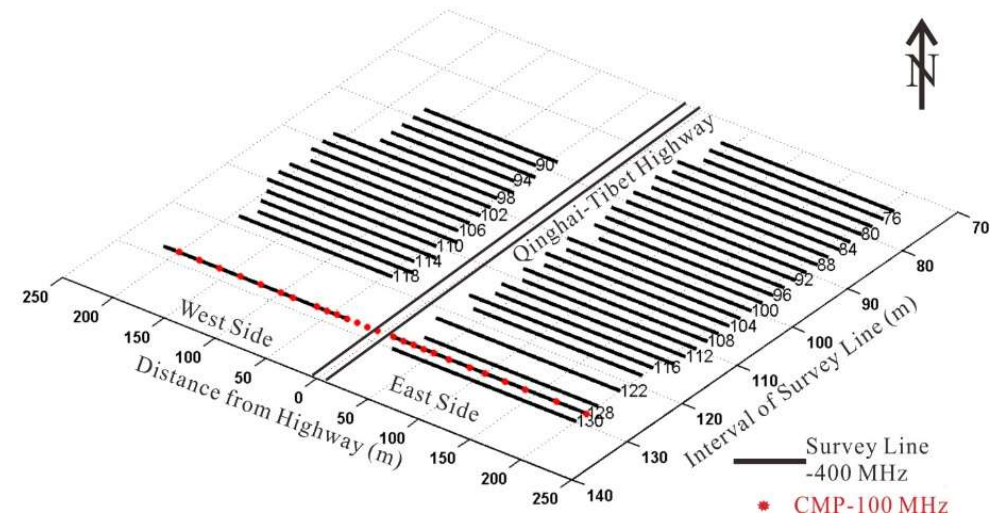

Figure 2. The diagram of survey lines at red box in Figure $1 b$, the red point is CMP site. The researchers used $100 \mathrm{MHz}$ antenna to collect the CMP gather, and used $400 \mathrm{MHz}$ antenna to collect the survey lines GPR data.

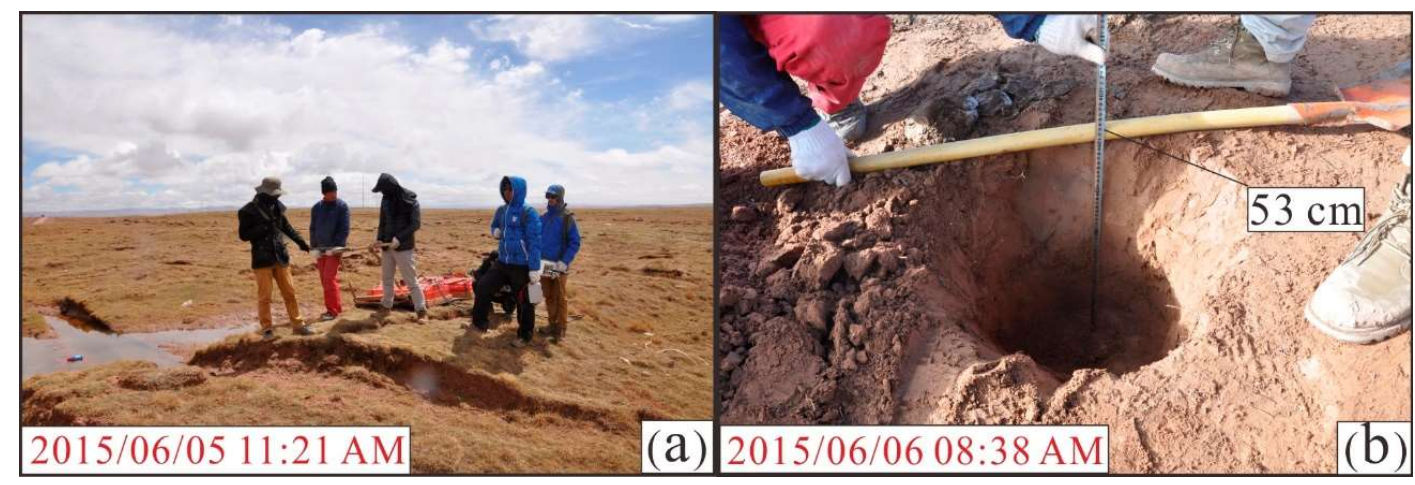

Figure 3. The photo pictures of the collected GPR data at the Beiluhe permafrost site (a); and test pit (b) on the west side of the Tibetan Highway (b), the depth of active layer is about $53 \mathrm{~cm}$ at the period time of the GPR surveys were carried out.

\subsection{Radar Wave Velocity}

The right propagation velocity is key to analyze the ALT and RTM imaging. The CMP is mainly used for detecting radar wave velocity. In our work, we applied the direct hyperbola fitting method to analyze the radar velocity for CMP gather and common-offset GPR profile. Based on the velocity analysis of CMP gather on the two sides of QTH, we can find the direct wave velocity is $0.10 \mathrm{~m} / \mathrm{ns}$ from Figure 4, the majority of subsurface radar velocity is increasing with the depth from $0.10 \mathrm{~m} / \mathrm{ns}$ to $0.12 \mathrm{~m} / \mathrm{ns}$. Figure 4 shows the subsurface radar velocity is $0.10 \mathrm{~m} / \mathrm{ns}$. Combining the dielectric constant of active layer [32], CMP gather (Figure 4) and GPR data velocity analysis (Figure 5), it can be concluded that the gradual changes velocity is reasonable (Figure 6). 

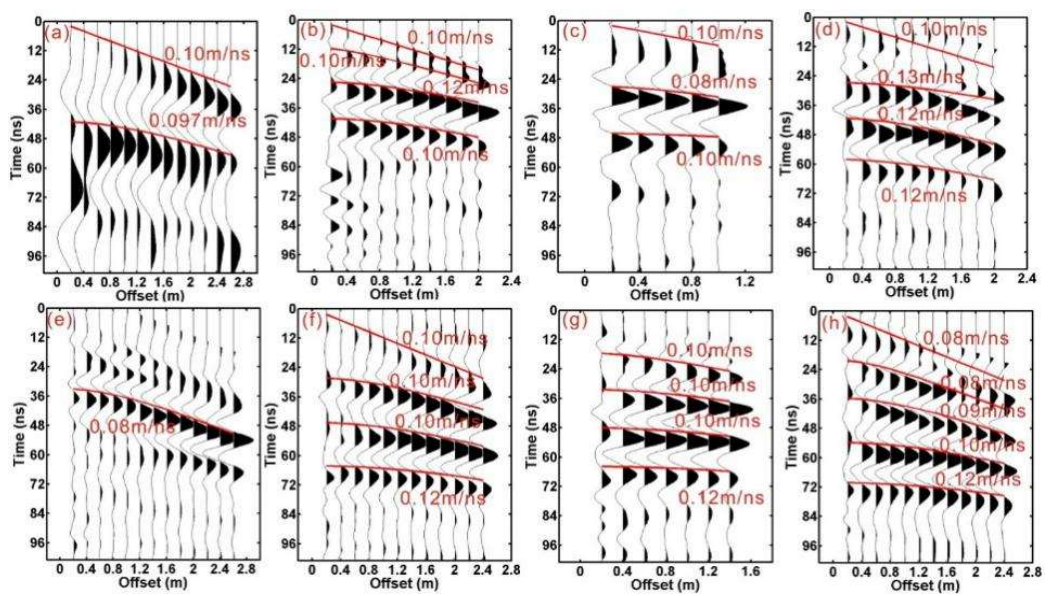

Figure 4. The velocity analysis of CMP gather using hyperbolic fitting method (a) W25; (b) W35; (c) W100; (d) E20; (e) $\mathrm{E} 30 ;$ (f) E50; (g) E85; (h) E100.

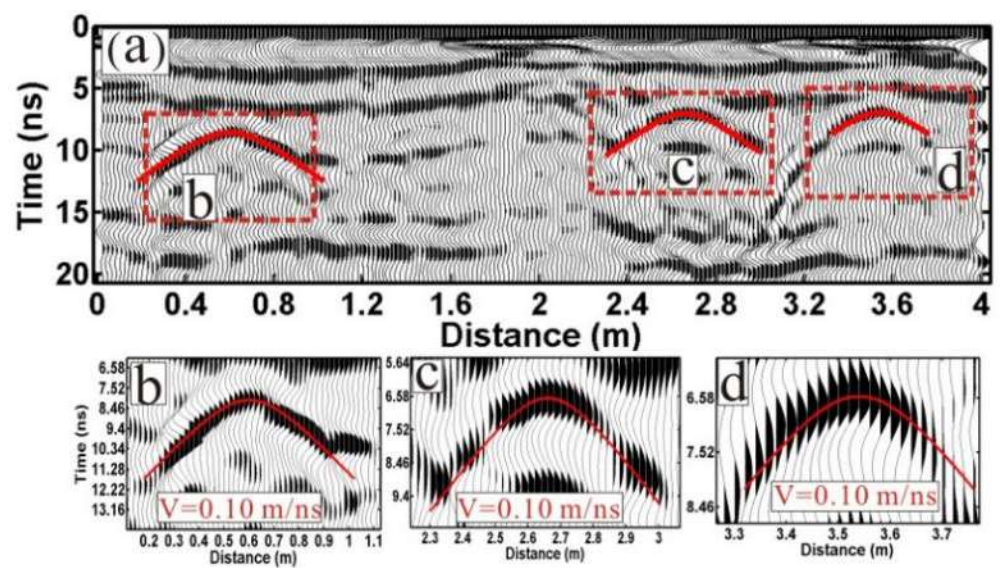

Figure 5. The velocity analysis of GPR profile using hyperbolic fitting method at the Line E106 from the QTH 101 m, (a) GPR profile; (b), (c) and (d) are hyperbolas.

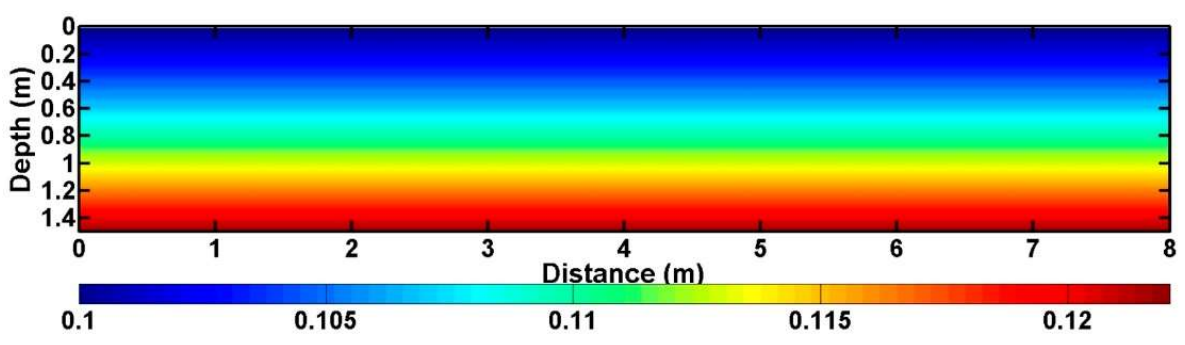

Figure 6. The graduate changes velocity model based on the result of hyperbolic fitting for CMP gather and GPR profile.

\section{Results}

The raw GPR profile shows complex reflection, diffraction on the subsurface in radar section. In order to obtain the detailed internal structure of the active layer and ALT, the researchers used RTM algorithm to process radar profile and obtain the RTM imaging.

\subsection{RTM imaging}


The discontinuous reflection at the $5 \mathrm{~ns}$ (the green lines in Figure 7) is caused by bottom interface of peat layer. The diffractions still exist in the Line W92 and Line W94 (Figure 7). There are a number of reflection events crossing and messing in the parts of Line W92 and Line W94 of Beiluhe permafrost region (Figure 7). The small reflection and discontinuous reflection of around 15 ns (the red lines in W92a in Figure 7) are difficult to reflect the actual internal structure of active layer. The irregular reflectors has migrated back to the properly position, appearing as two distinct reflection layers (the red lines in W92b and W94b in Figure 7). Pit data indicates the depth of bottom interface of active layer is about $0.6 \mathrm{~m}$ (the red line in W92b and W94b in Figure 7), appearing a relatively continuous and weak reflections at the bottom of active layer in RTM profiles (the W92b and W94b in Figure 7). The researchers think these weak reflections are from permafrost layer, and they have laterally changed the depth of active layer. The ALT is about $0.6 \mathrm{~m}$ in the migration sections (the W92 and W94 in Figure 7). The process of RTM can improve the lateral resolution, the RTM cross-section can clearly reflect the internal fine structure and ALT variation in distance.

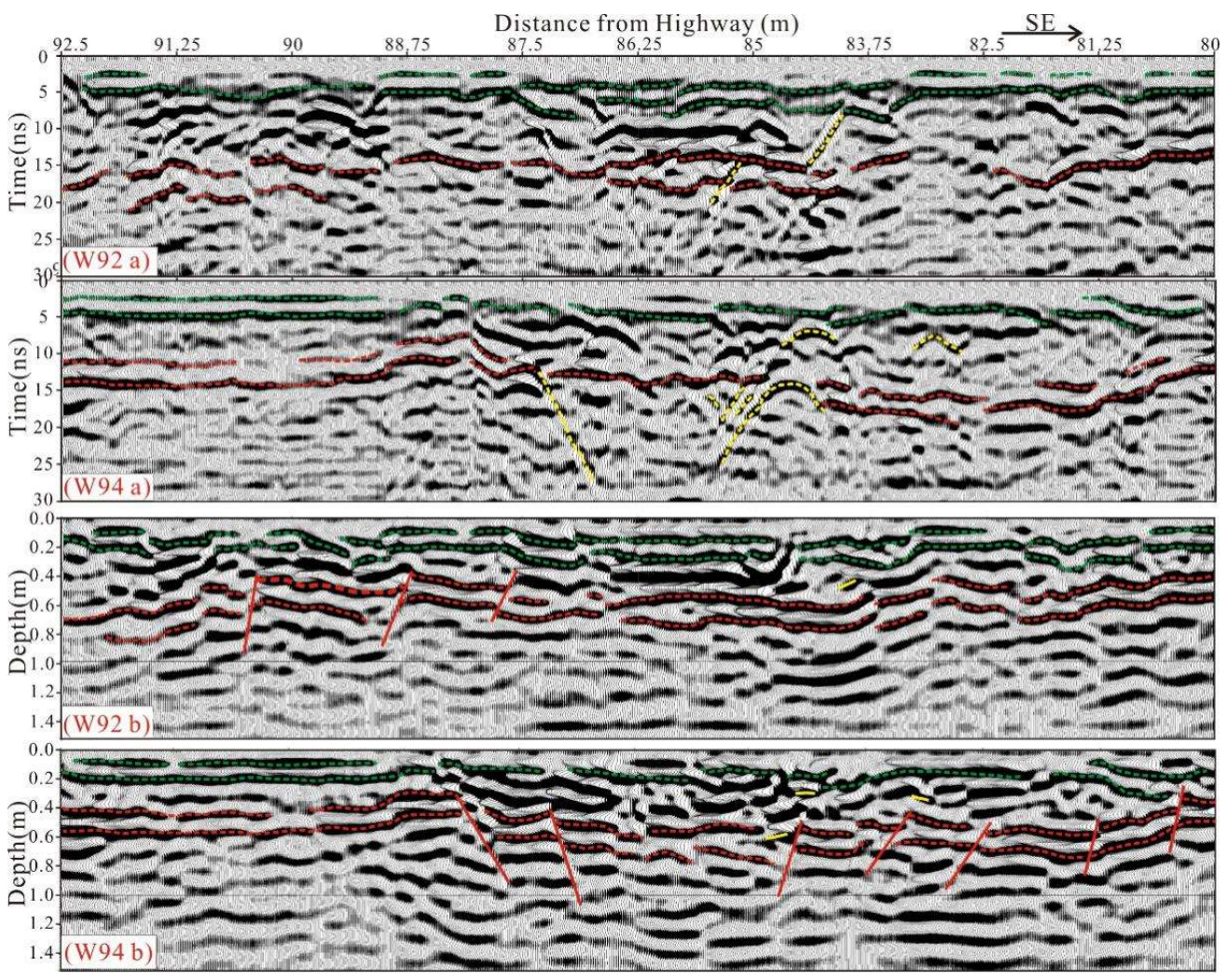

Figure 7. W92a and W94a are the portion of the original GPR cross-section of Line W92 and Line W94; W92b and W94b are the RTM result of (W92a and W94a), respectively.

\subsection{Responses to multiple small-scale grabens}

The drill data and geology information show that there are peat layer, fine sands and silts from top to bottom in Beiluhe region. The RTM profile of Line W92 and W94 (the W92b and W94b in Figure 7) show the internal fine structure is graben-like structure. Combining with the drill data, the interpretation of internal structure (the W92 and W94 in Figure 8) can clearly show the change of peat layer thickness, thawed active layer, permafrost and characteristic of internal reflection. Just like in Figure 8 show the graben-like internal structure, the researchers also found the same structure in 
another RTM profile in Line W108 (Figure 9) and Line W88 (Figure 10). From the RTM profile in Line W108, the researchers find the ALT is about 0.6 0.8 $\mathrm{m}$ (the red lines in Figure 9), and the depth of active layer have obviously deepen and the internal structure of active layer has obviously submerged from $41 \mathrm{~m}$ to $46 \mathrm{~m}$ in Figure 9. From $119.75 \mathrm{~m}$ to $123.5 \mathrm{~m}$, the internal structure of active layer is suddenly downward, and forms the graben-like structure from the RTM profile in Line W88 (the red lines and yellow lines in Figure 10).

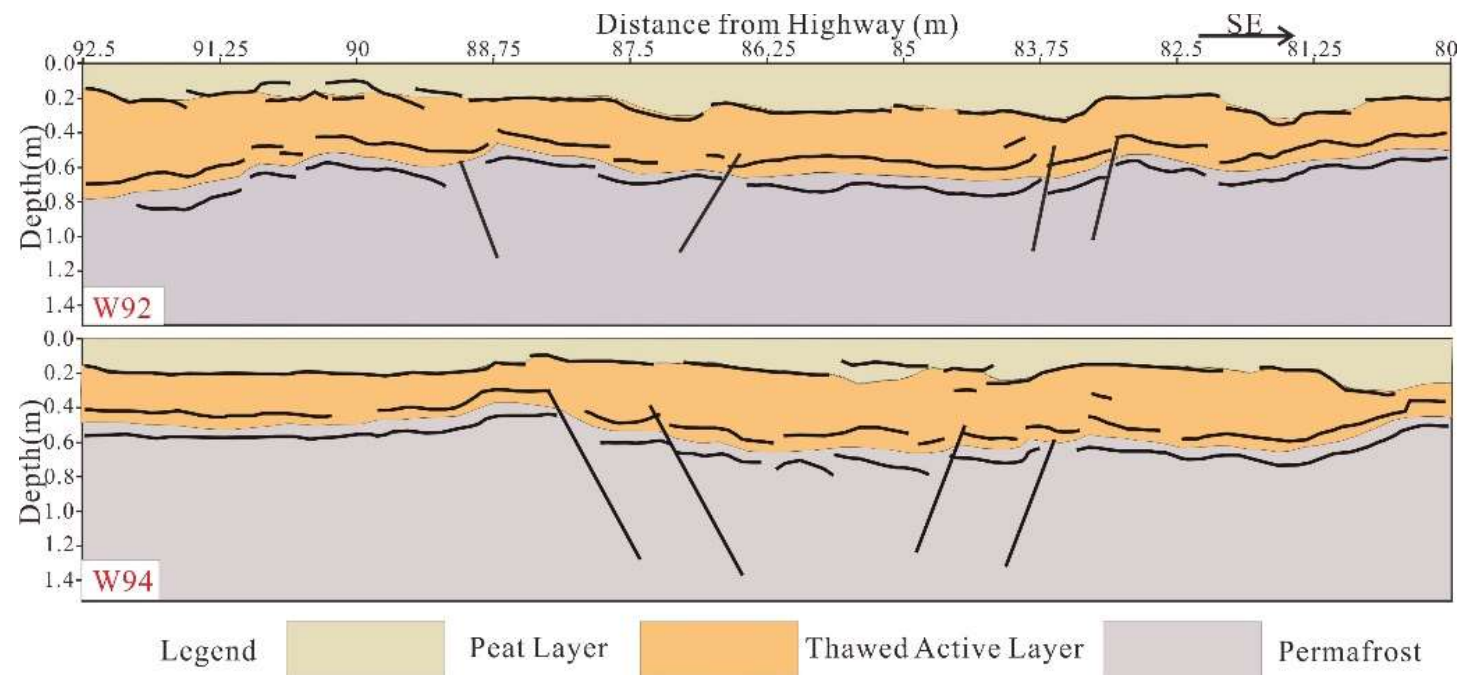

Figure 8. W92 and W94 are the portion of the interpretation result of Line W92 and Line W94.

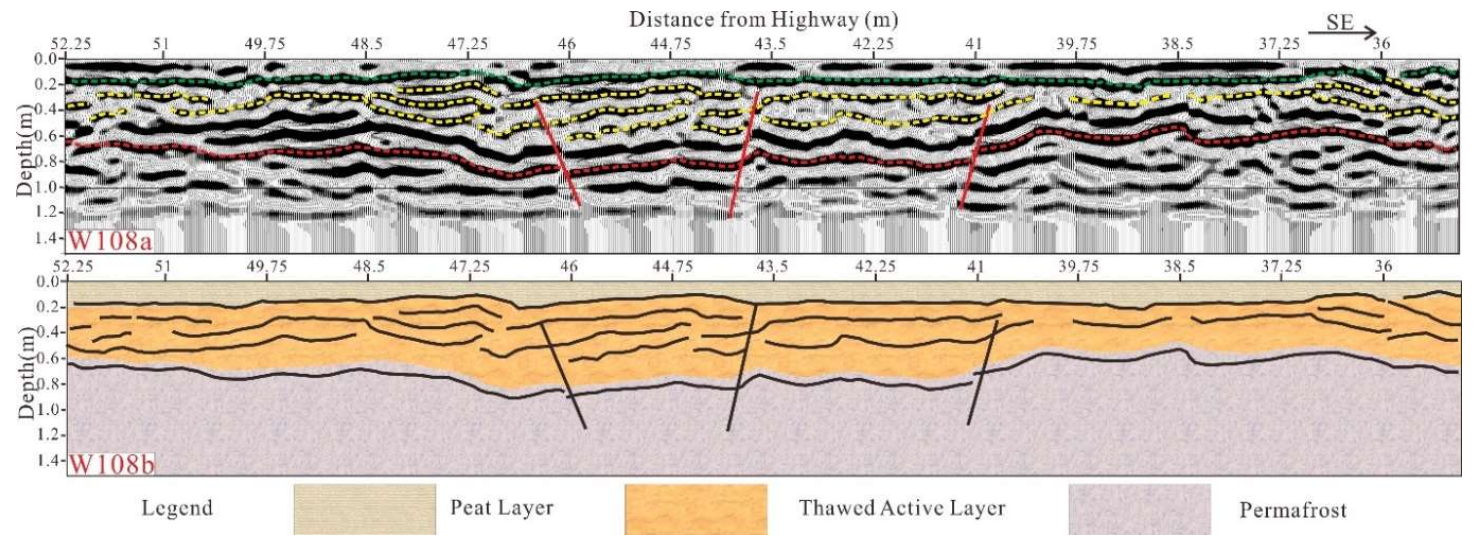

Figure 9. A portion of the RTM result (W108 a) and interpretation result (W108 b) of cross-section of Line W108. Green line are reflection events of the bottom of peat layer, yellow line is internal reflection events in the active layer, red line are reflection events of the bottom of the thawed active layer. 


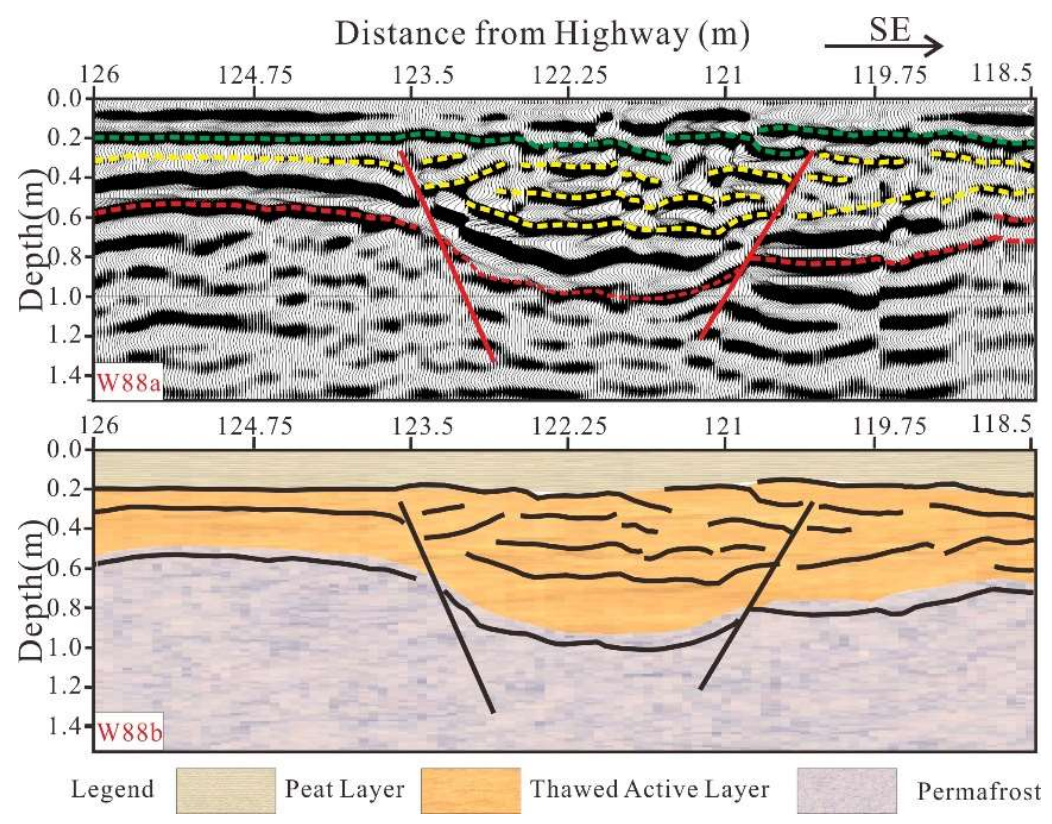

Figure 10. A portion of the RTM result (W88 a) and interpretation result (W88 b) of cross-section of Line W88. Green line are reflection events of the bottom of peat layer, yellow line is internal reflection events in the active layer, red line are reflection events of the bottom of thawed active layer.

\subsection{The formation mechanism of graben-like structure}

Comparing with RTM profile of the adjacent survey lines (Figure 8) and different survey lines (Figure 9 and Figure 10), the researchers found the graben-like structure in active layer at Beiluhe region. In this region, some scholars have researched the creep characteristic and process of thaw thump of frozen soil from the slop and surface landform [33]. Many factors will have influence on the ALT and internal structure of active layer, including the surface landforms, soil materials, and so on. The surface vegetation coverage is quite uniform in the entire survey area, except for near the highway. Thus, the researchers deduce the graben-like structures in the active layer are caused by the different soil materials. The Beiluhe region is located in high alluvial plain. The drill data and previous study shows that the formations mainly compose of Quaternary silt, pluvial fine sand, silt and silty clay layer, and peat layer in this region. Frozen soil types mainly compose of ice-rich permafrost and island permafrost.

The ice-layer of the active layer reserves the pore spaces at shallow surface soil. Due to different porosity in different types of soil, the ice contents have obvious differences. Generally speaking, the loose sandy gravels have larger porosity than the pluvial fine sands, silts and silty clay layers, resulting the ice contents are significantly higher in sandy gravel layer. With the ground temperature rising, the ice-rich permafrost of sandy gravel layer begins to melt. The sandy gravel layer will generate more melted water than pluvial fine sand under the same ground temperature condition. In addition, the sandy gravel layers have poor effect of heat insulation than pluvial find sand, and absorb more heat in the same ground temperature condition, which will accelerate the ice-rich permafrost thawing. The ice-rich permafrost thawing of sandy gravel layer will cause the stress loose for shallow soil, and form the larger subsidence in local area. The researchers deduce the larger subsidence is graben-like structure, which might be related to creep of frozen soil and hazards of subgrade settlement and deformation of QTH. 


\subsection{Active Layer Thickness}

Just like the Figure 10, the researchers picked the ALT from RTM profiles of entire survey lines, and made the 2D contour maps in Figure 11. Figure 11 shows the ALT spatial variation at the west and east sides of Tibetan highway in this period. The two images show the most of ALT is about 0.6 $\mathrm{m} \sim 0.8 \mathrm{~m}$. The ALT is about $0.9 \mathrm{~m}$ at some local regions (the box I 、 II III in Figure 11). The researchers separated two types for these local region, including far from the highway (the box III in Figure 11) and near the highway (the box I and box II in Figure 11). Combining with geomorphological information of shallow surface ( I and II in Figure 11), the researchers found the peat layers of shallow surface at the west side of highway have been destroyed (the photo picture (b) in Figure 11), and some plashes are far from the highway (the photo picture (c) in Figure 11) at the period of the GPR surveys.

In order to construct the QTH, some workers destroyed the vegetation coverage, and formed the low-lying terrain at the two sides of QTH. With permafrost active layer thawing, the plashes were formed at both sides of QTH. Due to lack of the protection of vegetation coverage for permafrost active layer, uncovered soil will absorb more heat at daytime and release more heat at night. This abnormal process will increase the specific heat capacity of subsurface soil and heat conductivity, and accelerate the thawing of permafrost active layer.

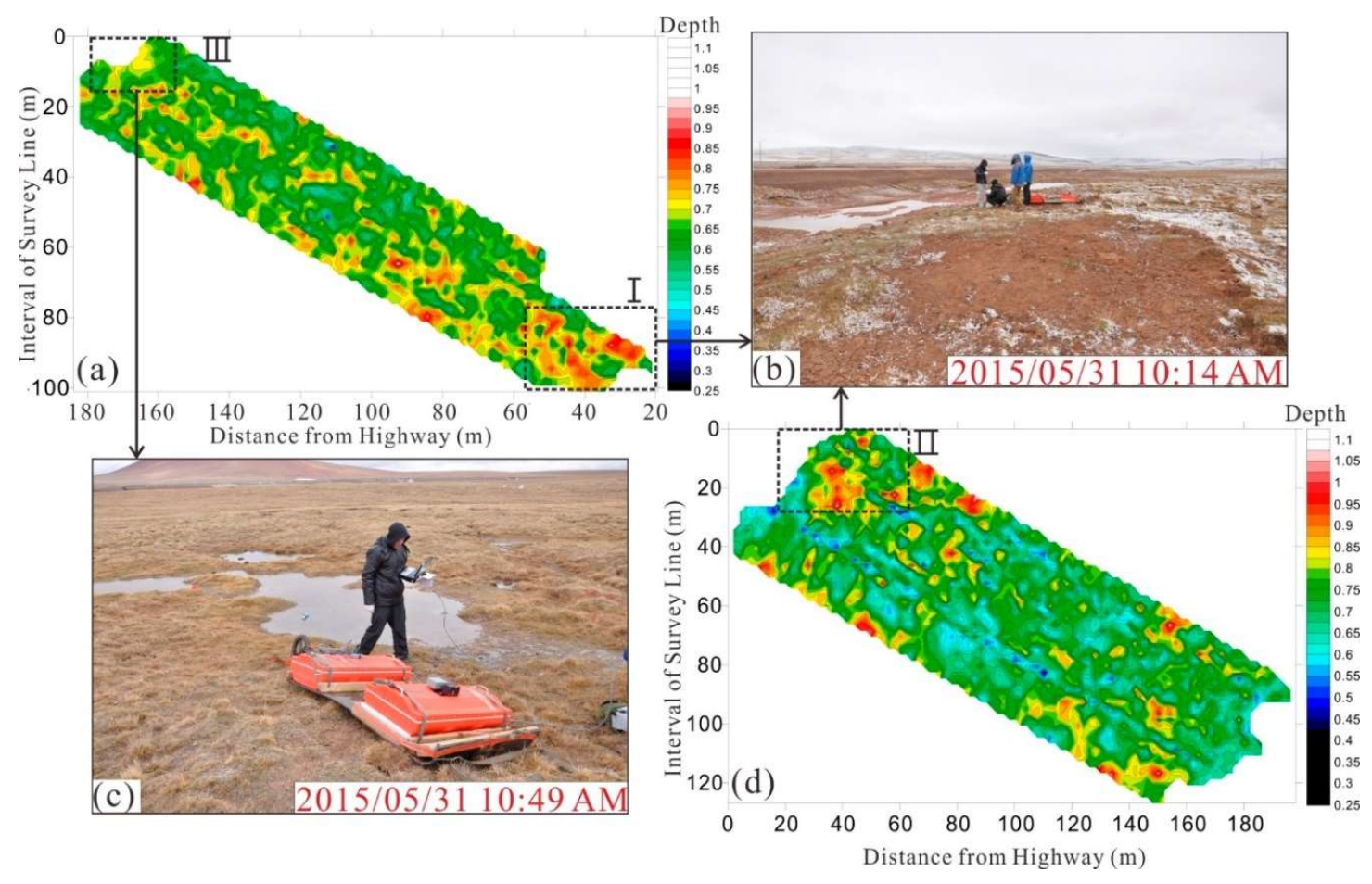

Figure 11. The two-dimensional contour map of ALT at west side (a) and east side (d) in Beiluhe site. The photo pictures of the landscape at the Beiluhe permafrost site: the close to the west side of Tibetan Highway (b), which correspond with the box I and II in map (a) and map(d); the west side and distance from Tibetan Highway is about 195 m (c), which correspond with the box III in map (a). 
Some scholars studied the thermokarst lakes will affect the ground temperature, and make the ground temperature rise, which will accelerate the thawing of active layer [33]. These theories correspond with the result of the GPR detection. Figure 12 shows the RTM profile and interpretation near the plash. The closer the plash, the deeper thawed active layer.

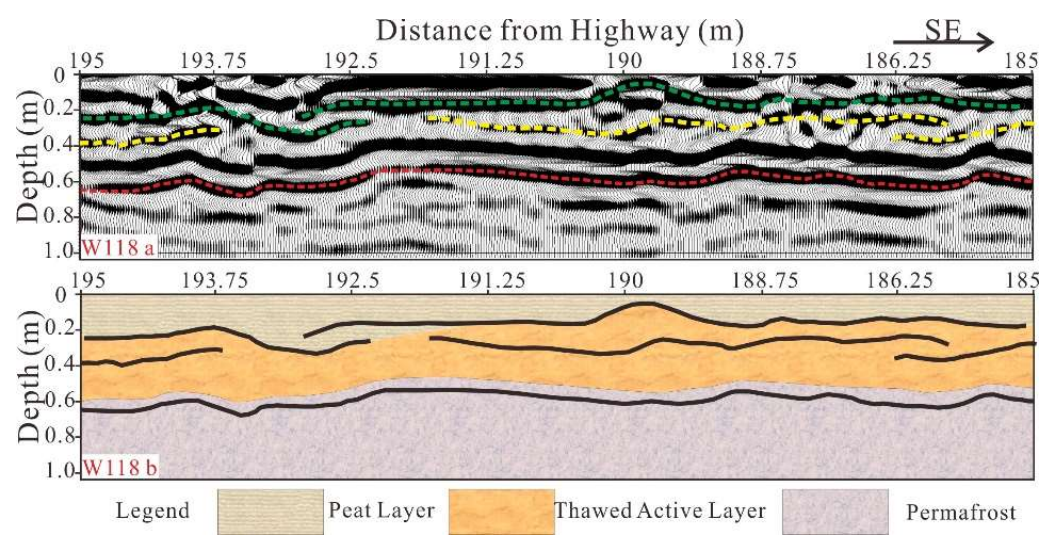

Figure 12. RTM profile (W118 a) and interpretation profile (W118 b) near the plash at the west side of QTH. Green line are reflection events of the bottom of peat layer, yellow line is internal reflection events in the active layer, yellow line is internal reflection events in the active layer, red line are reflection events of the bottom of thawed active layer, blue line is reflection events of permafrost.

\section{Discussion}

GPR profiles provide a wealth of interpretive information about active and permafrost layer. The right velocity is key to analysis the ALT and RTM imaging. It is well accepted that the ground permittivity has strong correlation with soil moisture [32]. With the active layer thawing, the ground permittivity will increase. Some scholar pointed out that the semblance analysis for CMP gather cannot achieve accurate velocity analysis, and be directly used in the hyperbolas fitting method, for examples Forte et al [34]. In another, Sham and Lai [35] developed the new algorithm to estimate the radar velocity for the common-offset GPR profile, and the algorithm is similar to hyperbolas fitting process. In this paper, we apply the direct hyperbola fitting method to analyze the radar velocity from CMP gather and radar profile. As shown in Figure 4, the direct wave velocity is $0.10 \mathrm{~m} / \mathrm{ns}$, the majority of subsurface radar velocity is increasing with the depth from $0.10 \mathrm{~m} / \mathrm{ns}$ to $0.12 \mathrm{~m} / \mathrm{ns}$. The velocity inside of the active layer is $0.10 \mathrm{~m} / \mathrm{ns}$ (Figure 5). Combining the geological information, the result of CMP gather and radar profile velocity analysis, the researchers adopted the gradual changing velocity model as the migration velocity.

Compared with the other migration methods [30], the RTM method has the great advantage of using full wave field information and adapts to the change of the lateral velocity of active layer medium. The RTM profiles show the detailed internal structure of the active layer (Figure 7, 9, 10, 12). The permafrost types are mainly frozen soil, ice-containing and ice-rich soil [12]. The formation of multiple small-scale grabens may be related to the island permafrost and ice-rich permafrost. The loose structure (the W92 in Figure 8) and graben-like structure (the W94 in Figure 8, Figure 9 and Figure 10) may be caused by the lateral variation of the soil materials that intensifies the variation of the mechanical strength due to the participation of groundwater freezing-thawing process.

The drill data and landforms information show the vegetation coverage was better in the Beiluhe region. The surface vegetable is mainly peat layer. GPR RTM cross-sections indicate that the depth of the bottom interface of the peat layer is about $0.2 \mathrm{~m}$. The 2D contour maps of ALT can show spatial 
information of ALT at the west and east side of the highway. The thickness of the active layer is in a range of $0.6 \sim 0.9 \mathrm{~m}$ in June 2015 .

In this region, the change of the ALT is mainly related to vegetation coverage and soil materials. The shallow surface soil is covered by the surface vegetation and peat layer in most areas, and the ALT is about $0.6 \mathrm{~m}$ in this region. Due to highway construction and human activities, the surface were destroyed (Figure 11b), and the ALT is about $0.8 \mathrm{~m} \sim 0.9 \mathrm{~m}$ near the highway (Figure 11a and Figure 11d). Some scholar pointed out that the ground temperature and ALT will have obvious change around the plash and thermokarst lakes (Sun et al., 2017). At the far away from the highway, the researchers found some plashes (Figure 11c), which correspond with the abnormal region (Figure $12)$.

\section{Conclusion}

In this paper, combining the geological information, pit excavation, and the RTM profiles based on GPR surveys in the Beiluhe region, the researchers presented a field study of the detailed features of the permafrost in the Tibetan plateau. The RTM profiles show graben-like internal structures while 2D contour maps indicate ALT at both sides of the QTH. The major findings can be summarized as follows:

Through GPR profiles and the zero-offset RTM algorithm, the researchers obtain the highresolution detailed active layer structures of the permafrost instead of merely the thickness of the active layer as most previous studies did. The study of the active layers in such details is rare compared with previous studies.

The RTM imaging results of GPR data reveal a wide diversity of active layer structures that are most likely controlled by soil types and ice content are far from highway. The graben-like loose structure might be related to soil materials. By the drill data and geological information, we concluded that these soil materials are most likely to be coarse gravel layer.

The 2D contour maps of ALT at west and east sides of highway can clearly reflect the ALT spatial information in this period, which will compensate the defect of the research for the single 2D survey line. The ALT is about $0.6 \mathrm{~m} \sim 0.8 \mathrm{~m}$ at the most parts of Beiluhe region, and is $0.8 \mathrm{~m}-0.9 \mathrm{~m}$ at two sides of the QTH. The formed plashes have affected the ALT at west side of QTH, the closer to the plash, the deeper the thawed active layer.

In future studies, the researchers will extend the approach presented in this paper to multiple times in a seasonal cycle to study the freezing-thawing process of active layer, and examine the relationships with soil properties, surface vegetation condition, and ground temperature, etc. With more surveys in multiple years and multiple locations accumulating, we expect to provide more constraints in climate change studies and more objective advice for infrastructure engineering construction in the Tibetan plateau. For example, one of our study is applied to estimate the availability of free water generated by the active layer that may severely affect the growth of the thermokarst lakes near the Qinghai-Tibet corridor.

Acknowledgments: The authors are grateful to the hard work of the field crew members to collect the valuable field data in rigorous field conditions of the high elevations in the Tibetan plateau.

Funding: This work was supported by the Natural Science Foundation of China (NSFC) through Project 41330634 . 
Authors Contribution: Xinglin Lu wrote the paper, editor RTM imaging algorithm, and process the GPR data. Ao Song, Jiwen Xiao and Zhenning Ma did the preliminary GPR data process. Rongyi Qian and Qingbai Wu provided GPR equipment and experimental scheme. All authors collected GPR data in the observation field.

Conflicts of interest: The authors declare no conflict of interest.

\section{References}

1. Brosten, T.R.; Bradford, J.H.; McNamara, J.P.; Gooseff, M.N.; Zarnetske, J.P.; Bowden, W.B.; Johnston, M.E. Estimating $3 \mathrm{D}$ variation in active-layer thickness beneath arctic streams using ground-penetrating radar. Journal of Hydrology 2009, 373, 479-486, doi:10.1016/j.jhydrol.2009.05.011.

2. Lupascu, M.; Welker, J.M.; Seibt, U.; Maseyk, K.; Xu, X.; Czimczik, C.I. High Arctic wetting reduces permafrost carbon feedbacks to climate warming. Nature Climate Change, 2014, 4, 51-55, doi:10.1038/nclimate 2058.

3. Schuur, E.A.G.; Mcguire, A.D.; Schadel, C.; et al. Climate change and the permafrost carbon feedback. Nature 2015, 520, 171-179, doi:10.1038/nature14338.

4. Li, R.; Zhao, L.; Ding, Y.J.; Wu, T.H.; Xiao, Y.; Du, E.J.; Lin, G.Y.; Qiao, Y.P. Temporal and spatial variations of the active layer along the Qinghai Tibet Highway in a permafrost region. Chinese Science Bulletin 2012, 57, 4609-4616, doi:10.1007/s11 434-012-5323-8.

5. Peng, H.; Ma, W.; Mu, Y.H.; Jin, L.; Yuan, K. Degradation characteristics of permafrost under the effect of climate warming and engineering disturbance along the Qinghai-Tibet Highway. Nat Hazards. 2015, 75, 2589-2605, doi:10.1007/s11- 06901414445.

6. Xiao, J.; Liu, L. Permafrost subgrade condition assessment using extrapolation by deterministic deconvolution on multi-frequency GPR data acquired along the Qinghai-Tibet railway. IEEE Journal of Selected Topics in Applied Earth Observations and Remote Sensing 2015, 9, 1-8, doi:10.1109/JSTARS. 2015.24 87970.

7. Pang, Q.Q.; Zhao, L.; Li, S.X.; Ding, Y. Active layer thickness variations on the Qinghai-Tibet Plateau under the scenarios of climate change. Environment Earth Science 2012, 66, 849-857, doi:10.1007/s12665-011-1296-1.

8. Yang, M.X.; Nelson, F.E.; Shiklomanov, N.L.; Guo, D.L.; Wan, G.N. Permafrost degradation and its environmental effects on the Tibetan Plateau: A review of recent research. Earth-Science Reviews 2010, 103, 31-44, doi:10.1016/j. earscirev.2010.07.002.

9. Haeberli, W.; Whiteman, C.; Shroder, J.F. Snow and Ice-Related Hazards, Risks, and Disasters: Chaper.10. Permafrost Degradation, Elsevier 2015.

10. Wu, T.H.; Li, S.X.; Cheng, G.D.; Nan, Z.T. Using ground penetrating radar to detect permafrost degradation in the northern limit of permafrost on the Tibetan Plateau. Gold Regions Science and Technology 2005, 41, 211-219, doi:10.101 6/j.Coldregions.2004.10.006.

11. You, Y.H.; Yu, Q.H.; Pan, X.C.; Wang, X.B.; Guo, L. Application of electrical resistivity tomography in investigating depth of permafrost base and permafrost structure in Tibetan Plateau. Cold Regions Science and Technology 2013, 87, 19-26, doi:10.10 16/j.coldregions.2012.11.004.

12. Wen, Z.; Zhang, T.J.; Sheng, Y.; Ma, W.; Wu, Q.B.; Feng, W.J.; Sun, Z.Z. Managing ice-rich permafrost exposed during cutting excavation along Qinghai-Tibetan railway: Experiences and implementation. Engineering Geology 2011, 122, 316-327, doi: 10. 1016/j.enggeo.2011.07.012.

13. Niu, F.J.; Lin, Z.J.; Lin, H.; Lu, J.H. Characteristics of thermokarst lakes and their influence on permafrost in Qinghai-Tibet Plateau. Geomorphology 2011, 132, 222-233, doi:10.1 016/j.geomorph.2011.05.011.

14. Wu, Q.B.; Zhang, P.; Jiang, G.L.; Yang, Y.Z.; Deng, Y.S.; Wang, X.B. Bubble emissions from thermokarst lakes in the Qinghai-Xizang Plateau. Quaternary International 2014, 321, 65-70, doi:10.1 016 /j.quaint.2013.11.028.

15. Yang, Y.Z.; Wu, Q.B.; Yun, H.B.; Jin, H.J.; Zhang, Z.Q. Evaluation of the hydrological contributions of permafrost to the thermokarst lakes on the Qinghai-Tibet Plateau using stable isotopes. Global and Planetary Change 2016, 140, 1-8, doi:10.1016/j.gloplacha.2016.03.006.

16. Lin, Z.J.; Niu, F.J.; Fang, J.H.; Luo, J.; Yin, G.A. Interannual variations in the hydrothermal regime around a thermokarst lake in Beiluhe, Qinghai-Tibet Plateau. Geomorphology 2017, 276, 16-26, doi: 10.1016/j.geomorph. 2016.09.035.

17. Wu, Q.B.; Shen, Y.P.; Shi, B. Relationship between frozen soil together with its water-heat process and ecological environment in the Tibetan Plateau. Journal of Glaciology and Geocryology 2003, 25, 250-255, doi:10.3969/j.issn.1000-0240.2003.03.002. 
18. Wu, Q.B.; Hou, Y.D.; Yun, H.B.; Liu, Y.Z. Changes in active-layer thickness and near-surface permafrost between 2002 and 2012 in alpine ecosystems, Qinghai-Xizang (Tibet) Plateau, China. Global and Planetary Change 2015, 124, 149-155, doi:10.101 6/j.gloplacha.2014.09.002.

19. Yu, F.; Qi, J.L.; Yao, X.L.; Liu, Y.Z. In-situ monitoring of settlement at different layers under embankments in permafrost regions on the Qinghai-Tibet Plateau. Engineering Geology 2013, 160, 44-53, doi: 10.1016/j.enggeo.2013.04.002.

20. Yin, G.A.; Niu, F.J.; Lin, Z.J.; Luo, J. Effects of local factors and climate on permafrost conditions and distribution in Beiluhe basin, Qinghai-Tibet Plateau, China. Science of the Total Environment 2017, 581, 472-485, doi:10.1016/j. scitotenv.2016.12.155.

21. Arcone, S.A.; Delaney, A.J.; Strasser, J.C.; Strasser, J.D. Ground penetrating radar reflection profiling of groundwater and bedrock in an area of discontinuous permafrost. Geophysics 1998, 63, 1573-1584, doi:10.1190/1.1444454.

22. Schwamborn, G.J.; Dix, J.K.; Bull, J.M.; Rachold, V. High resolution Seismic and Ground Penetrating radar Geophysical Profiling of a Thermokarst Lake in the Western Lena Delta, Northern Siberia. Permafrost and Periglacial Processes 2002, 13, 259-269, doi:10.1002/ppp.430.

23. Jorgensen, A.S.; Andreasen, F. Mapping of permafrost surface using ground-penetrating radar at Kangerlussuaq Airport. Western Greenland. Gold Regions Science and Technology 2007, 48, 64-72, doi:10.1016/j.coldregions. 2006.10. 007.

24. Wollschlager, U.; Gerhards, H.; Yu, Q.; Roth, K. Multi-channel ground-penetrating radar to explore spatial variations in thaw depth and moisture content in the active layer of a permafrost site. The Cryosphere 2010, 4, 269-283, doi: 10.5194/tc-4-269-2010.

25. Chen, S.; Liu, W.; Qin, X.; Liu, Y.; Zhang, T.; Chen, K.; Hu, F.; Ren, J.; Qin, D. Response characteristics of vegetation and soil environment to permafrost degradation in the upstream regions of the Shule River Basin. Environment research letters 2012, 7, 45406-45416, doi:http://dx.doi.org/10.1088/1748-9326/7/4/04 5406.

26. Wainstein, P.; Moorman, B.; Whitehead, K. Glacial conditions that contribute to the regeneration of Fountain Glacier proglacialicing, Bylot Island, Canada. Hydrol Process 2014, 28, 2749-2760, doi:10.1002/hyp.9787.

27. Merz, K.; Maurer, H.; Buchli, T.; Horstmeyer, H.; Green, A.G.; Springman, S.M. Evaluation of Ground Based and Helicopter Ground Penetrating radar Data Acquired Across an Alpine Rock Glacier. Permafrost and Periglacial Processes 2015, 26, 13-27, doi:10.1002/ppp.1836.

28. Liu, L.; Qian, R.Y. Ground Penetrating Radar: A critical tool in near-surface geophysics. Chinese Journal Geophysics 2015, 58, 2606-2617, doi:10.6038 /cjg20150802.

29. Wu, Z.H.; Barosh, P.J.; Hu, D.G.; Wu, Z.H.; Ye, P.S.; Liu, Q.S.; Zhou, C.J. Migrating pingos in the permafrost region of the Tibetan Plateau, China and their hazard along the Golmud-Lhasa railway. Engineering Geology 2005, 79, 267-287, doi:10.1016/j.enggeo.2005.02.003.

30. Li, S.; Fomel, S. Kirchhoff migration using eikonal based computation of travel time source derivatives. Geophysics 2013, 78, 211-219.

31. Bradford, J.H. Reverse time prestack depth migration of GPR data from topography for amplitude reconstruction in complex environments. Journal of Earth Science 2015, 26, 791-798, doi:10.1007/s12583-015-0596-X.

32. Du, E.J.; Zhao, L.; Wu, T.H.; Li, R.; Yue, G.Y.; Wu, X.D.; Li, W.P.; Jiao, Y.L.; Hu, G.J.; Qiao, Y.P.; Wang, Z.W.; Zou, D.F.; Liu, G.Y. The relationship between the ground surface layer permittivity and active-layer thawing depth in a Qinghai-Tibetan Plateau permafrost area. Cold Regions Science and Technology 2016, 126, 55-60, doi:10.1016/j.coldregions. 2016.03. 006.

33. Sun, Z.; Wang, Y.B.; Sun, Y.; Niu, F.J.; Li, G.Y.; Gao, Z.Y. Creep characteristics and process analyses of a thaw slump in the permafrost region of the Qinghai-Tibet Plateau, China. Geomorphology 2017, 293, 1-10, doi:10.1016/j. geomorph.2017.04.045

34. Forte, E.; Dossi, M.; Colucci, R.R.; Pipan, M. A new fast methodology to estimate the density of frozen materials by means of common offset GPR data. Journal of Applied Geophysics 2013, 99, 135-145, doi: 10.1016/j.jappgeo.2013.08.013.

35. Sham, Janet, F.C.; Lai, Wallace, W.L. Development of a new algorithm for accurate estimation of GPR's wave propagation velocity by common-offset survey method. NDT and E International. 2016, 83, 104-113, doi: 10.1016/j.ndteint.2016.05.002. 